\title{
The Renin-Angiotensin-Aldosterone System in Patients with Cystic Fibrosis of the Pancreas
}

\author{
A. P. Simopoulos ${ }^{191}$, A. Lapey, 'T. F. Boat, P. A. di Sant' Agnese, and F. C. Bartter \\ Endocrinology Branch, National Heart and Lung Institute, and Pediatric Metabolism Branch, National Institute of Arthritis and \\ Metabolic Diseases, National Institutes of Health, Bethesda, Maryland, USA
}

\begin{abstract}
Extract
Patients with cystic fibrosis of the pancreas (CFP) have elevated plasma renin activity, supine renin 497-595 compared with a normal value of $228 \pm 133 \mathrm{ng} / 100 \mathrm{ml}$ plasma on $109 \mathrm{mEq}$ sodium intake $/ 24 \mathrm{hr}$, but have normal renin release mechanisms as far as postural changes are concerned, since the renin activity increases normally with the upright posture; upright renin, 594-875 compared with a normal value of $359 \pm$ $210 \mathrm{ng} / 100 \mathrm{ml}$ plasma on the same sodium intake. The high aldosterone secretion rates (ASR), $161-445$ compared with a normal value of $90 \pm 31 \mu \mathrm{g} / 24 \mathrm{hr}$, seen on 109 $\mathrm{mEq}$ sodium intake were probably secondary to the abnormally high renin release. The same can be said for the lack of adequate suppression to normal of both renin and ASR on $249 \mathrm{mEq}$ sodium intake/24 hr, supine renin $205-544$ compared with a normal value of $97 \pm 71 \mathrm{ng} / 100 \mathrm{ml}$ plasma; upright renin $845-893$ compared with a normal value of $212 \pm 61 \mathrm{ng} / 100 \mathrm{ml}$ plasma; ASR on the same intake, 93-333 compared with a normal value of $62.15 \pm 27.8 \mu \mathrm{g} / 24 \mathrm{hr}$. The low metabolic clearance rates and the high calculated plasma aldosterone concentrations on the $109 \mathrm{mEq}$ sodium intake indicate that a state of secondary hyperaldosteronism exists in patients with CFP, probably as an adaptation to frequent, excessive sodium losses via the sweat and consequent contraction of intravascular volume.
\end{abstract}

\section{Speculation}

In all the patients that we studied with cystic fibrosis of the pancreas a state of secondary hyperaldosteronism appears to exist. This state of hyperaldosteronism, secondary to increased renin release, probably results from adaptation to frequent, excessive sodium losses via the sweat, leading to depletion of extracellular fluid volume.

\section{Introduction}

Cystic fibrosis of the pancreas (CFP) is a hereditary clisease of children. Although the basic defect is not known, there is general agreement that the abnormality results from an inborn error of metabolism transmitted as an autosomal recessive trait. The triad of chronic pulmonary disease, pancreatic deficiency, and abnomally high sweat electrolyte concentration is present in most patients. The sweat electrolyte abnormality is present from birth and throughout life and is not related either to the severity of the underlying disease or to the involvement of other organs such as the pancreas or lungs [6].

In normal subjects, reduced losses of sodium and chloricle in the sweat have been known to accompany the process of acclimatization to heat [13]; however, in 
patients with CFP, perspiration resulting from sudden rises in environmental temperature may lead to massive salt loss and to vascular collapse [6]. The adrenal cortex is implicated in these and other changes of acclimatization. There is ample evidence to indicate that exposure to heat results in increased adrenocortical secretion of aldosterone [13]. Aldosterone is the main salt-active steroid secreted by the adrenal cortex, promoting transport of sodium, potassium, and hydrogen ions by renal tubular and other cells, and is of importance in the normal control of fluid and electrolyte balance. Physiologic secretion of aldosterone is controlled by: (I) a function of extracellular fluid volume, (2) angiotensin II (and probably less importantly), (3) ACTH, and (4) potassium ions [4]. Presumably, there are other unknown control mechanisms. Sodium depletion increases the secretion of aldosterone from the adrenal cortex. This effect can be attributed in part to stimulation of production of renin, and thus of angiotensin. It is well known that, when normal subjects are depleted of sodium, renin release and aldosterone production are increased. Upon sodium repletion both renin and aldosterone secretion rates return to normal.

There is some evidence that sweat glands in patients with CFP do have some response to exogenous aldosterone administration and that the endogenous aldosterone excretion and secretion respond to salt losses [6, 9]. Therefore, it cannot be said that such individuals cannot "acclimatize" to hot weather. The sweat $\mathrm{Na}$ and Cl levels, however, are abnormally high even after the decrease. The role of the renin-angiotensin system in the regulation of aldosterone production has been studied extensively in normal subjects and in hypertensive individuals. This paper reports on the relationship of the renin-angiotensin-aldosterone system in patients with CFP.

\section{Materials and Methods}

Five patients, ranging in age from $138 / 12$ to 21 years, had been followed regularly over a period of years by the Pediatric Metabolism Branch of NIAMD (Tables I and II).

All patients were admitted to an air-conditioned unit 1 week prior to initiating the investigation and were confined continuously to this unit for the several weeks of the study [15]. Four patients were studied in the summer (July and August 1969 and 1970), but patient $J A$ was studied in October 1969. Patient $J A$ was readmitted for further investigation in the summer of 1970 as were $S Y$ and $J Y$ (Table III).
Table I. Clinical data ${ }^{l}$

\begin{tabular}{|c|c|c|c|c|c|}
\hline \multirow{2}{*}{$\begin{array}{c}\text { Patients } \\
\text { with CFP }\end{array}$} & \multirow{2}{*}{ Sex } & \multirow{2}{*}{ Age, yr } & Weight & Height & \multirow{2}{*}{$\mathbf{M}^{2}$} \\
\hline & & & \multicolumn{2}{|c|}{ percentile } & \\
\hline$S B$ & F & 21 & 3 & 5 & 1.2 \\
\hline$A B$ & $F$ & 17.5 & 5 & 5 & 1.25 \\
\hline$S Y$ & $\mathbf{F}$ & 17 & 3 & 5 & 1.28 \\
\hline$J I^{r}$ & $F$ & 14 & 10 & 5 & 1.35 \\
\hline$J A$ & $\mathbf{M}$ & 13.3 & 5 & 25 & 1.3 \\
\hline
\end{tabular}

${ }^{1}$ Five patients with cystic fibrosis of the pancreas (CFP).

The design of the experiment is shown in Figure 1. Each subject was studied under strict metabolic regimen on three different sodium intakes, 109, 9, and 249 $\mathrm{mEq} / 24 \mathrm{hr}$ for 8 -day periods; on $50 \mathrm{mEq} / 24 \mathrm{hr}$ potassium throughout the study; and on a constant fluid intake. Twenty-four-hour urine pools were collected daily and analyzed for sodium and potassium. A sweat test was performed twice during each 8-day period by iontophoresis of $0.2 \%$ pilocarpine nitrate at different skin sites, on two subsequent days. The concentrations of sodium and chloride in the sweat were expressed in milliequivalents per liter. The sodium in the sweat and the sodium and potassium in the urine were determined in a flame photometer with lithium as an internal standard. (No attempt was made to incorporate net sweat loss into the balance results.) Chloride was determined with a chloridemeter [16]. The subjects were weighed daily before breakfast after voiding, and serum electrolyte values were obtained every 4 days. During each 8-day period of different sodium intake, alclosterone secretion rate (ASR), aldosterone metabolic clearance rate (MCR), and plasma renin activity were measured. On this study, ASR and MCR were measured simultaneously. After the patient had breakfast, he walked to the metabolic clearance room where the MCR was measured by the constant infusion method with the patient in the supine position over a 2-hr period. A "primer" dose of $2.5 \mu \mathrm{Ci}{ }^{3} \mathrm{H}$-aldosterone (specific activity $1.0 \mu \mathrm{Ci} / \mathrm{ml}$ ) was given intravenously at the beginning of the infusion. Thirty minutes later infusion of a solution of ${ }^{3} \mathrm{H}$-aldosterone and normal saline was begun at a rate of $0.191 \mathrm{ml} / \mathrm{min}$ and continued, using a constant infusion pump, for the next 90 min. The patient received $24.2 \mathrm{~m} \mu \mathrm{Ci} / \mathrm{min}$. Blood was sampled in heparinized syringes at 90,105 , and $120 \mathrm{~min}$ from the time the primer close was given. The plasma was kept frozen until extracted. Determinations were carried out by the method of Tait [12].

The ASR was measured by a modification of the method of Kliman and Peterson [8] as previously de- 
Table II. Biochemical and endocrinc data

\begin{tabular}{|c|c|c|c|c|c|c|c|c|}
\hline \multirow{2}{*}{\multicolumn{2}{|c|}{ P'atients with CFP }} & $\mathrm{CO}_{2}$ & \multirow{2}{*}{$\mathrm{pCO}_{2}, \mathrm{~mm} \mathrm{Hg}$} & \multirow{2}{*}{$\mathrm{pHI}$} & 17OIICS & $17 \mathrm{KS}$ & \multirow{2}{*}{$\begin{array}{l}\mathrm{GFR}, \\
\mathrm{ml} / \mathrm{min}\end{array}$} & \multirow{2}{*}{$\mathrm{TP} / \mathrm{A}^{1}, \mathrm{~g} / \mathrm{s00} \mathrm{ml}$} \\
\hline & & $\mathrm{mLa} /$ liter & & & \multicolumn{2}{|c|}{$\mathrm{mg} / 2 \mathrm{thr}$} & & \\
\hline$S B$ & 4.2 & $30-37$ & 42 & 7.40 & 3.8 & 3.5 & 119 & $7.7 / 3.8$ \\
\hline$A / B$ & 4.3 & $28-34$ & 36 & 7.43 & 5.7 & 6.5 & 125 & $8.8 / 4.3$ \\
\hline$S Y$ & 3.9 & $28-31$ & 40 & 7.43 & 5.5 & 2.9 & 107 & $7.3 / 4.2$ \\
\hline$J Y$ & 3.7 & $26-29$ & 39 & 7.40 & 10.4 & 4.2 & 111 & $7.1 / 4.2$ \\
\hline$J A$ & 3.9 & $26-27$ & 42 & 7.42 & 6.3 & 1.9 & 89 & $7.2 / 3.8$ \\
\hline
\end{tabular}

1 TP: total protein, $A$ : albumin.

Table III. Effect of prolonged salt loading on the renin-angiotensin-aldosterone system in three patients with cystic fibrosis of the pancreas ${ }^{1}$

\begin{tabular}{|c|c|c|c|c|c|}
\hline \multirow{2}{*}{$\begin{array}{l}\mathrm{Pa}- \\
\text { tients } \\
\text { with } \\
\mathrm{CIP}\end{array}$} & \multicolumn{2}{|c|}{ Sweat ${ }^{2}$} & \multicolumn{2}{|c|}{ Renin } & \multirow{2}{*}{ ASK $^{2}$} \\
\hline & $\mathrm{Na}$ & $\mathrm{Cl}$ & $\mathrm{S}^{2}$ & $\mathrm{U}^{2}$ & \\
\hline $\begin{array}{l}\text { Normal } \\
\text { SY }\end{array}$ & & & $\begin{array}{c}97 \pm 71 \\
358\end{array}$ & $\begin{array}{c}212 \pm 61 \\
845\end{array}$ & $62.15 \pm 27.8$ \\
\hline $\begin{array}{l}s \gamma \\
J Y\end{array}$ & $\begin{array}{l}113.8 \\
113.8\end{array}$ & 108.4 & $\begin{array}{l}350 \\
205\end{array}$ & 851 & $\begin{array}{r}93 \\
120\end{array}$ \\
\hline$J .1$ & 94.4 & 70.2 & 448 & 893 & 134 \\
\hline
\end{tabular}

This areat of the study was for 12 days with an intake of $249 \mathrm{mEq} / 24 \mathrm{hr}$ of sodium. All three patients were studied in July and August in an air-conditioned unit (see text).

Sweat $\mathrm{Na}$ and $\mathrm{Cl}$ in milliequivalents per liter. $\mathrm{S}$ : supine renin; and $\mathrm{U}$ : upright renin in nanograms per $100 \mathrm{ml}$ of plasma. ASR : aldosterone secretion rale, in micrograms per $24 \mathrm{hr}$.

scribed from this laboratory [5]. Plasma renin was measured by a modification of the method of Boucher [2] as previously described from this laboratory [10]. The sample was taken at 8:00 $\mathrm{N}$ a after the patient had been supine for 8-10 hr. After breakfast the patient remained in the upright position until 12:00 noon when the "upright" renin sample was taken. For this study the MCR was carried out between 9:00 AM and 11:00 AM, and the samples for renin were taken the next day.

To establish that patients do not suppress the reninangiotensin-aldosterone system on salt-loading, three of the five patients were readmitted and given $249 \mathrm{mEq}$ sodium/24 hr for 12 complete metabolic days. The patients were almitted 1 week prior to the study, remained in the air-conditioned unit $24 \mathrm{hr} /$ day, and were given a high salt intake. Following this l-week period they were studied on a metaloolic regimen of $2.19 \mathrm{mE}$ g sodium $/ 24 \mathrm{hr}$. At the end of the 12-day period ASR testing was performed. Renin activity in both supine and upright positions was determined the following day. Sweat tests by iontophoresis were performed after renin activity had been determined.

Blood volume measurements were not performed becatuse hypovolemic changes had presumably occurred at frequent intervals prior to admission. Angiotensin infusions were thought to be contraindicated if any cardiac involvement was present, and renal biopsies were not justifiable.

\section{Results}

Figure 1 shows a typical balance study on patient JY. The serum sodium, potassium, and $\mathrm{CO}_{2}$ concentra-

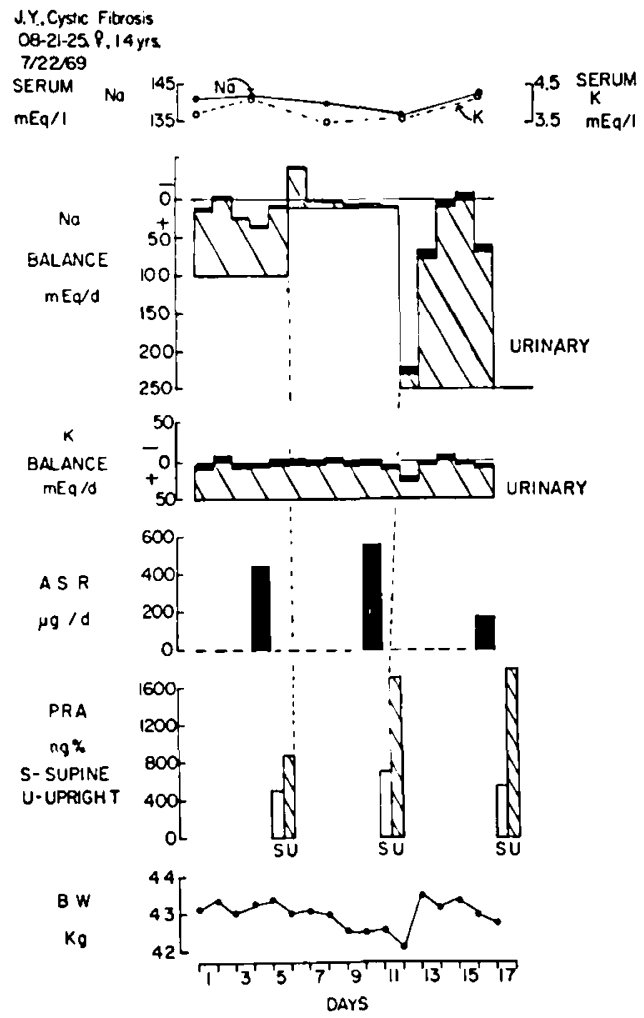

Fig. 1. Scrum sodium $(\mathrm{Na}$ ) and potassium $(\mathrm{K})$, sodium and potas. sium balance, aldosterone secretion rate (ASR), plasma renin activity (PRA), and body weight in a 14 -year-old girl with cystic fibrosis of the pancreas. The balance data are plotted as follows: intake is plotted downward from the zero line; urinary (hatched) and fecal (black) output are plotted upward from the intake ins. Thus, negative balance is shown by shaded areas above the zero line, positive balance by clear areas below it. 


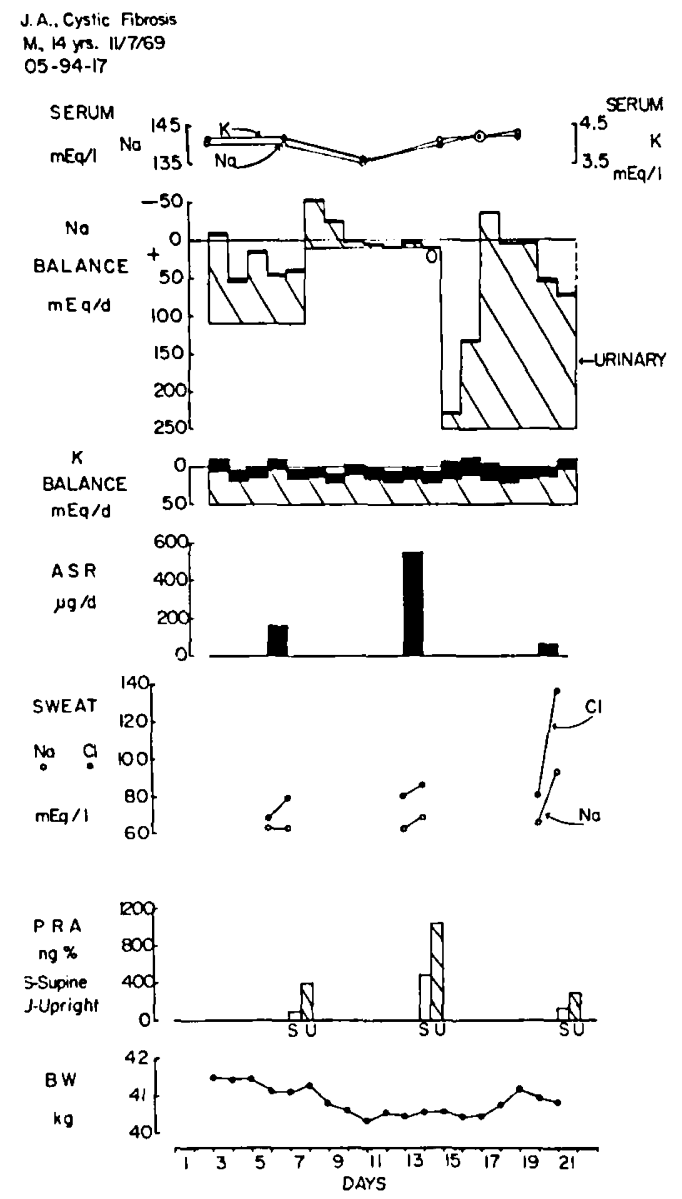

Fig. 2. Serum $\mathrm{Na}$ and $\mathrm{K}, \mathrm{Na}$ and $\mathrm{K}$ balance, $\mathrm{ASR}$, sweat $\mathrm{Na}$ and chloride $(\mathrm{Cl})$, PRA and body weight in a 14-year-old boy with cystic fibrosis of the pancreas. Sec legend to Figure 1.

tions (not shown) remained within the normal range. None of the patients became hypokalemic. On the 109 $\mathrm{mEq}$ sodium intake the patients appeared to be in positive balance. On the $9 \mathrm{mEq}$ sodium intake there was a striking decrease in urinary $\mathrm{Na}$ levels and patients appeared to return to balance by the 5th day; in all patients the urinary sodium had clropped to zero by the 7 th day. On the $249 \mathrm{mE}$ sodium intake the patients appeared to be in positive balance. Serum potassium remained normal throughout the 8-day periods of high salt intake.

Figure 2 represents the balance study on another patient with addlition of sodium and chloride concentrations in sweat. The sweat glands continue to secrete sodium and chloride excessively despite the low salt intake; on the high salt intake, even higher concentrations of sodium and chloride are lost in the sweat [11, 12]. Thus, although the patients appear to be in positive balance when intake and fecal and urinary out- puts for sodium are plotted, they may be in negative balance when the sodium concentration in sweat is taken into consideration. This is also reflected in the changes in weight experienced by the patients on the three different sodium intakes (Fig. 3). All patients lost weight on the $9 \mathrm{mEq}$ sodium intake; three failed to regain the weight despite a change to a salt intake of $249 \mathrm{mEq} / 24 \mathrm{hr}$. The other two patients gained only a small amount.

\section{Aldosterone Metabolism}

Figures 1 and 2 show that the ASR increased on the $9 \mathrm{mEq}$ sodium intake; ASR values are plotted of all patients on the 109,9 , or $249 \mathrm{mEq}$ sodium intake as are values for normal subjects. All patients except one receiving $109 \mathrm{mEq}$ sodium had elevated ASR. The increase in aldosterone production seen with the change to a $9 \mathrm{mEq}$ intake was somewhat less than that seen in normal subjects (Fig. 4). On the $249 \mathrm{mEq}$ sodium intake ASR did not suppress to normal levels except in one patient $(J A)$. This patient was the youngest of the five studied and the one least affected as regards pulmonary involvement. In addition, $J A$ was the only one of the five patients to be studied in a cooler season (October 1969) rather than the summer season (July-
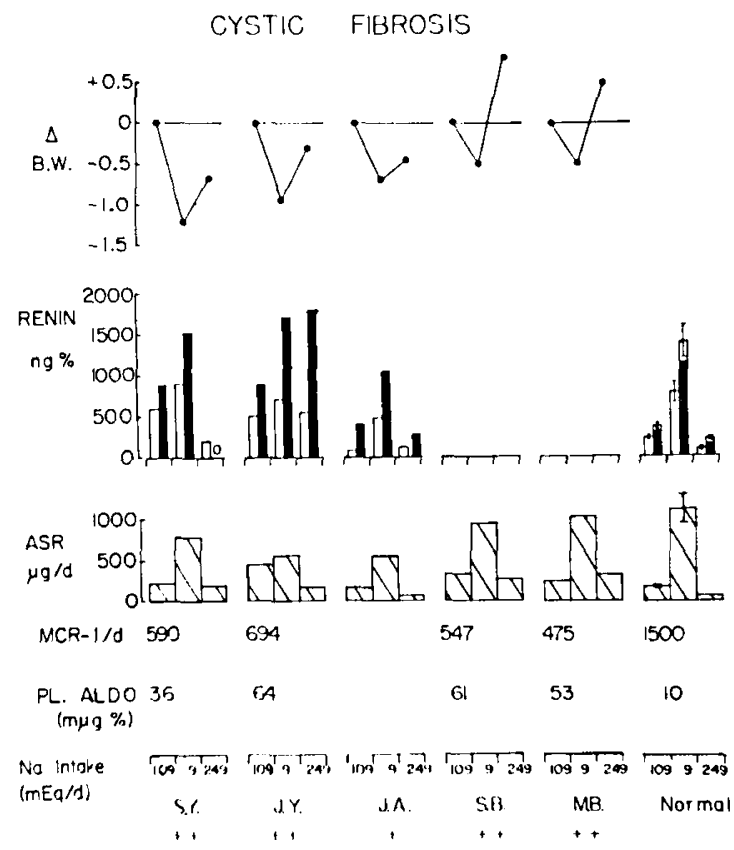

Fig. 3. Summary of all data on the five patients on the three differcnt sodium intakes. Blank bars (II) indicate supine and black bars (I) upright PRA. The data for $J A$ represent values obtained during the October study, while all the other were performed in summer (August). 


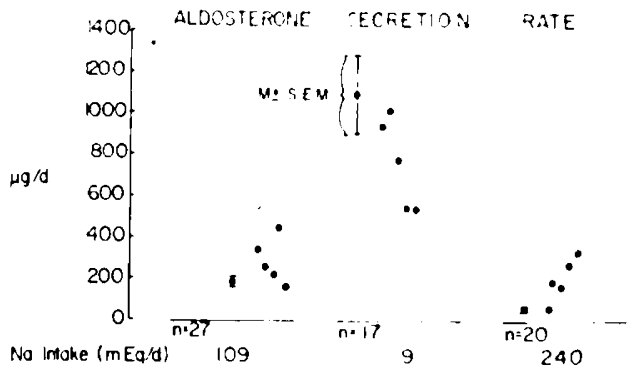

Fig. 1. Aldosterone secretion rates of patients with cystic fibrosis of the pancreas and of normal coutrols receiving 109, 9, or 249 mlig scklimm/24 hr.

August 1969) as were the others. When $J A$ was studied again, in the summer of 1970 (August), he also failed (1) suppress adequately (Table III) and produced values similar to those found in the other patients studicel.

The XICR of aldosterone was below normal in all subjects on the $109 \mathrm{mEq}$ sodium intake. Patients had been up for $2 \mathrm{hr}$ before MCR of aldosterone were measured. The MCR of aldosterone is normally proportional to the hepatic blood flow [3, 14]. The MCR and the hepatic blood flow are highest after the patient has been in the supine position, decrease when the upright posture is assuned, and decrease even further when the patient has been in the upright position for $8 \mathrm{hr}$. Variations in ASR with changes of posture over short periods of time have not yet been defined. As mentioned in the section on Materials and Methols, the ASR and MCR were measured simultaneously. The patient was upright before the MCR; the procedure was carried out after he had assumed the supine position. The ASR was determined on a $24-\mathrm{hr}$ urine after the patient had been up for the remainder of the day until 8:00 PM, when he went to bed. Normal subjects were handled in the sime manner. Plasma aldosterone $(i)$ is then calculated indirectly as follows: $i=A S R / M C R$. Thus, with $A S R$ normal or high and MCR low, plasma aldosterone concentration was elevated in all the patients in whom it was measured.

\section{Renin-Angiotensin System}

By the method used [10], renin activity is expressed in nanograms of angiotensin 11 generated from endogenous substrate by endogenous renin per $100 \mathrm{ml}$ of plasma cluring 3 hr of incubation. In all patients in whom renin was measured it was clear that the renin activity increased when they changed from the supine to the upright position (Fig. 3). On $109 \mathrm{mEq}$ sodium intake, renin activity was moderately high; renin did not suppress normally with the $249 \mathrm{mli}$ intake except in one patient. Again, this patient was the youngest and the least affected of the five patients studied. Since the patients failed to gain the expected weight on the high salt intake, it is likely that renin production remained elevated because they continued to lose sodium in the sweat and presumably had reduced circulating blood volumes.

\section{Studies on the Renin-Angiotensin-Aldosterone: System after 12 Day's of Sodium Loading}

Table III lists the results obtained after the 12-dily sodium load in patients $S Y, J Y$, and $J A$. Plasmia renin values were $2-1$ times thit found in normal subjects and the ASR 1.5-2 times normal values. This establishes that the secondary hyperaldosteronism seen in patients with CFP cannot be suppressed with sodium loading.

\section{Discussion}

Aldosterone is the most potent electrolyte-ictive hormone produced by the wona glomerulosa of the adrenal cortex. Aldosterone accelerates the reabsorption of sodium ions in the kidney tubules, the salivary and sweat glands, and the gastrointestinal mucosa. There are at least three well defined mechanisms controlling aldosterone release from the adrenal glands: adrenocorticotropic hormone, plasma potassium concentration, and the renin-angiotensin system. Sodium depletion and the consequent decrease in circulating blood volume stimulate renin activity.

Although some decrease in sweat electrolyte levels occurs, patients with ClP' continue to secrete excessive amounts of sodium and chloride in the sweat regardless of a low sodium intake and of their response to administration of exogenous aldosterone $[6,7,12]$. This prompted us to stuly the responses of the reninangiotensin-aldosterone system on three different sodium intakes. The effect of posture on renin activity was also studied.

Patients with CFP have nomal renin release mechanisms as far as postural changes are concerned since renin activity increases nomally with the upright posture (Fig. 3). With patients in the supine position, plasma renin activity was higher than normal in the two moderately affected paticnts, but within the normal range in the mildly affected, younger patient. The clevated plasma renin levels seen in the two moderately affected patients on the $109 \mathrm{mEq}$ sodium intake most likcly reflects reduction of circulating blood vol- 
Ime secondary to excessive loss of sodium in the sweat. Renin activity rose on the low salt intake in a manner similar to that seen in normal individuals. It clid not, however, suppress on the high salt intake; further, unlike normal individuals, the patients with CFP failed to gain the expected weight on the high salt intake, presumably because of continued, or augmented, loss of sodium and chloride in the sweat. Presumably, intravascular volume does not expand adequately to "turn off" renin release (Fig. 3).

The high ASR found on the $109 \mathrm{mEq}$ sodium intake was probably secondary to the abnomally high renin release. The same can be said for the lack of suppression to normal on the high sodium intake in all patients except $J A$, during his first study (Fig. 2) in October 1969. Of interest is the fact that even after prolonged salt loading all the patients restudied continued to have elevated renin activity and ASR, possibly indicating that the defects in the renin-angiotensin-aldosterone system may not have resulted solely from long-standing sodium depletion. The low metabolic clearance rates and the high calculated plasma aldosterone concentrations on the $109 \mathrm{mE}$ sodium intake indicate that a state of secondary hyperaldosteronism exists in patients with CFP, probably as an adaptation to frequent, excessive sodium losses via the sweat and consequent contraction of intravascular volume. This sequence of events is made even more probable by the fact that when $J A$ was studied in August 1970 after weeks of excessive salt sweat losses he failed to suppress adequately, whereas during a cooler season (October 1969) he had a normal response in this respect.

Although this study represents at small series of pattients, it appears that the older and most affected patients have higher degrees of hyperaldosteronism. Montalvo and his associates [9] did not find elevated ASR in the patients they studicd. The discrepancy in his results and ours could reflect the type of patients studied, since patient $J A$, who was the least affected in our series, had normal ASR on $109 \mathrm{mEq} \mathrm{Na}$ intake/24 hr. A larger series of patients must be studied to establish clearly any relation between severity of clisease and the degree of hyperaldosteronism.

\section{Summary}

Five patients with cystic fibrosis of the pancreas (CFP), ranging from 13 to 21 years of age, were studied on an air-conditioned metabolic unit on constant dietary regimens with daily sodium intakes of 9, 109, or 249 $\mathrm{mEq} / 2.1 \mathrm{hr}$ for 8 -lay periods. The renin-angiotensin-al- dosterone system was studied on the different $\mathrm{Na}$ intakes.

The data indicate elevated plasma renin activity which responds normally to changes in posture. The aldosterone secretion rate was elevated on $109 \mathrm{mEq}$ $\mathrm{Na} / 24 \mathrm{hr}$, increased further on $9 \mathrm{mEq} \mathrm{Na} / 24 \mathrm{hr}$, but failed to suppress on $249 \mathrm{mEq} \mathrm{Na} / 24 \mathrm{hr}$. The metabolic clearance of alclosterone was decreased on 109 $\mathrm{mEq} / 24 \mathrm{hr}$ and the calculated plasma aldosterone concentration was increased. This state of hyperaldosteronism secondary to renin release probably results from adlaptation to frequent excessive sodium losses via the sweat, with consequent contraction of extracellular volume. A larger series of patients must be studied to establish clearly any relation between severity of discase and the degree of hyperaldosteronism.

\section{References and Notes}

1. BARTIEk, F. C.: The role of aldosterone in normal homeostasis and in certain disease states. Metabolism, 5: 369 (1956).

2. Boucher, R., Veyrat, R., DeChamplain, J., and Genest, J.: New procedures for measurement of human plasma angiotensin and renin activity levels. Can. Med. Ass. J., 90: 194 (1961).

3. Bougas, J., Floon, C., Little, B., Thit, J. F., TAit, S. A. S., AND UNDl:kwoon, R.: Dynamic aspects of aldosterone metabolism. In: E. E. Bauilicu and P. Robel: Aldostcrone, a Symposium, p. 25. (Blackwell, Oxford, 1964).

4. Burwei.r, L. R., David, W. W., and Barter, F. C.: Studies on the loci of action of stimuli to the biogenesis of aldosteronc. Proc. Roy. Soc. Med., 62: 1254 (1969).

5. Bryan, G. T., KIIMAN, B., AND BArtTer, F. C.: Impaired aldosterone production in "salt-losing" congenital adrenal liyperplasia. J. Clin. Invest., $f 1: 957$ (1965).

6. id Sanr' Agnfese, 1'. A., and 'Talano, R. C.: Pathogenesis and physiopathology of cystic fibrosis of the pancreas. New Engl. J. Med., 277: 1287 (1967).

7. Grani, R. J., di Sant' Agnese, P. A., Talamo, R. C., And Pailacicini, J. C.: Fffects of exogenous aldosterone on siveat electrolytes. II. Patients with cystic fibrosis of pancreas. J. Pediat., 70: 357 (1967).

8. Ki.man, B., ANI l'eterson, R. E.: Double isotope derivative assay of aldosterone in biological extracts. J. Biol. Chem., 235: $1639(1960)$.

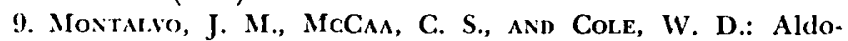
sterone metabolism in children with cystic fibrosis $(C / F)$ and their parents. J. Clin. Endocrinol. Metab., 28: 582 (1968).

10. Newsome, H. R., AND BARTter, F. C.: Plasma renin activity in relation to serum sodium concentration and body fluid bal. ance. J. Clin. Endocrinol. Metab., 28 : 1704 (1968).

11. Oriviz, W. J., AND Watson, D. F.: Effect of salt intake on sweat electrolytes in children. Amer. J. Dis. Child., 107: 470 (1961).

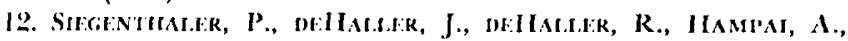
AND Muste, A. F.: Effect of experimental salt depletion and aldosterone lead on sodium and chloride concentration in 
sweat of patients with cystic fibrosis of pancreas and of normal children. Arch. Dis. Childhood, 39: 61 (1961).

13. SikteteN, D. H. P., CoN. W. J., Louis, H. L., FAjINS, S. S., Sfltzer, II. S., Jolisson, D. R., Gittler, D. R., ANi l) bis:, II. A.: Secondary aldostcronism: metabolic and adrenororticall responses of normal men to high environmental temperatures. Metabolism, 9: 1071 (1960)).

14. 'Tait, J. F., Lithi.., B., 'Tair, S. A. S., ANd Flood, C.: Tlic metabolic clearance rate of aldosterone in pregnant and non-pregnant subjects estimated by both single injection and constant infusion methols. J. Clin. Invest., 41: 2093 (1963).

15. Informed consent has been received in accordance with the provisions set forth in the Declaration of I Ielsinki.
16. Cotlove, Ametican Instrument Company, Silver Spring, Md.

17. We wish to thank Dr. Robert H. Schwartz of the University of Rochester Medical school for having referred to us for this study two of his priticuts.

18. Presented in part at the Seventy-Ninth Amsual Meeting of the American Pediatric Society and the Society for Pediatric Research, April 30 10 .lay 2, 1969.

19. Requests for reprints should be addressed to: Aktfons P. Smovoutos, M.1.,. Nattional Research Council-. Sational Academy of Science, 2101 Constitution Arenue N.W.. Washington, 1). C. 20418 (CS.I).

20. Accepted for publication December $28,1970$.

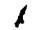

